\title{
Rosuvastatin-induced responses in calf cardiac vein
}

\author{
Nurullahoglu-Atalik $\mathrm{KE}^{1}, \mathrm{Oz} \mathrm{M}^{2}$, Shafiyi $\mathrm{A}^{1}$ \\ Necmettin Erbakan University Meram Medicine Faculty Department of Pharmacology, Konya Turkey. \\ esraatalik@hotmail.com
}

\begin{abstract}
OBJECTIVE: The effects of Rho-kinase inhibitors on vasodilatation induced by 3-hydroxy-3-methylglutaryl coenzyme A (HMG-CoA) reductase inhibitor rosuvastatin $\left(10^{-9}-10^{-4} \mathrm{M}\right)$ on 5-HT-precontracted calf cardiac vein and the role of endothelium in these effects were analyzed.

MATERIAL AND METHODS: Cardiac vein ring preparations were suspended in organ baths containing $25 \mathrm{ml}$ of Krebs-Henseleit solution, maintained at $37{ }^{\circ} \mathrm{C}$ and continuously gassed with $95 \% \mathrm{O}_{2}-5 \% \mathrm{CO}_{2}$. At the end

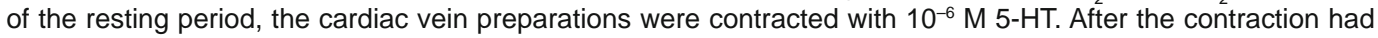
reached a steady state, rosuvastatin was added to the organ bath cumulatively $\left(10^{-9}-10^{-4} \mathrm{M}\right)$.

RESULTS: Rosuvastatin relaxed the cardiac vein rings in general while the degree of relaxation was greater in those with endothelium and lower in those without it. HA1077 [1-(5-isoquinolinesulfonyl)-homopiperazine] (Fasudil, 10-6 M) and Y-27632 [(+)-(R)-trans-4-(1-aminoethyl)-N-(4-pyridyl) cyclohexane carboxamide dihydrochloride] $\left(10^{-6} \mathrm{M}\right)$ incubation increased the rosuvastatin-induced relaxation only in the presence of endothelium. CONCLUSIONS: The results demonstrate for the first time that in calf cardiac vein, rosuvastatin induced endothelium-dependent relaxations while Rho-kinase inhibition increased these relaxations in the presence of endothelium layer (Fig. 3, Ref. 44). Text in PDF www.elis.sk.

KEY WORDS: calf cardiac vein, endothelium-dependent relaxation, Rho-kinase, rosuvastatin.
\end{abstract}

\section{Introduction}

In addition to their beneficial effects on lipid modulation, statins exert a variety of "pleiotropic" actions that may be clinically beneficial $(1,2)$. Indeed, the pleiotropic effects of statins have been considered to be as important as their hypolipemiant effects in the prevention of cardiovascular diseases (3). Examples of the pleiotropic actions of statins such as pravastatin, cerivastatin, atorvastatin, simvastatin, and rosuvastatin (4-6) include direct acute vascular effects associated with increased production of either endothelial nitric oxide synthase (eNOS or NOS-3) in endothelial cells (7) or inducible NOS (iNOS or NOS-2) in smooth muscle cells (8), antithrombotic effects, and anti-inflammatory effects (9).

A substantial number of experimental and clinical studies have demonstrated the favorable cardiovascular effects of rosuvastatin, one of the most commonly employed statins. These effects are generally associated with endothelial function. Among the endogenous regulatory systems of vascular tone, the vascular endothelial tissue plays a very important role. The cells of this tissue produce vasoactive substances in response to diverse chemical and hemodynamic

${ }^{1}$ Necmettin Erbakan University Meram Medicine Faculty Department of Pharmacology, Konya Turkey, and ${ }^{2}$ Mevlana University School of Health Services, Konya Turkey

Address for correspondence: K.E. Nurullahoglu Atalik, Department of Pharmacology, Faculty of Meram Medicine, University of Necmettin Erbakan, Konya, 42080,Turkey.

Fax: +90.332 .2237124$

Acknowledgement: This study is supported by the Scientific Research Foundation of Necmettin Erbakan University. factors that act on their receptors $(10,11)$. The balance between endothelial-derived contractile and relaxant factors under normal and pathological conditions determines the tone and the physical state of the vascular smooth muscle. The endothelium-dependent vascular relaxation is mainly mediated by nitric oxide (NO) and to a lesser extent by prostacyclin and endothelial-derived hyperpolarizing factor (EDHF). Thus, endothelial-derived NO plays an important physiological role in the regulation of blood pressure and blood flow and is commonly used as a marker of endothelial function (12). Cardiovascular diseases such as arteriosclerosis are closely associated with endothelial dysfunction. Thus, it is important to identify drugs such as statins, which are able to restore the normal activity of dysfunctional endothelium, prevent damage to this tissue, or stimulate its relaxant and antithrombic activity. It is well known that statins can block cholesterol synthesis and thus reduce cholesterol levels, which justifies their therapeutic use to lower the risk of cardiovascular disease (13-16). However, the effects of statins appear to be diverse and depend upon the vasculature studied $(17,18)$. Studies also found that Rho/ROCK pathway inhibition might contribute to the pleiotropic effects of statin therapy (19).

Recent advances in molecular biology have elucidated the important role of small GTP binding proteins (G proteins) such as Rho, Ras, Rab, Sarl/Arf, and Ran families in mediating various cellular functions (17). Rho is known to modulate $\mathrm{Ca}^{2+}$ sensitization of vascular smooth muscle (VSMC) and is thought to act by inhibiting myosin phosphatase activity $(17,18)$. Rho-kinase plays an important role in mediating various cellular functions, for example VSMC contraction $(17,20)$. Rho-kinase is involved 
in endothelial contraction that increases endothelial permeability and hence enhances atherosclerosis $(21,22)$. Taken together, the accumulation of evidence suggests that Rho-kinase is substantially involved in the pathogenesis of a wide spectrum of cardiovascular diseases. Antagonism of Rho/Rho-kinase pathway may result in smooth muscle relaxation $(23,24)$. Endogenous NO raises levels of cGMP, vascular smooth muscle relaxes, and the vessel lumen enlarges. This leads to increased expression of protein kinase $\mathrm{G}(\mathrm{PKG})$. The vasodilator action of the cGMP/ PKG pathway also decreases cytosolic $\mathrm{Ca}^{2+}$ and causes $\mathrm{Ca}^{2+}$ desensitization by increased MLCP activity (25). Moreover, statins increase eNOS mRNA stability by inhibiting Rho GTPases, including RhoA, to increase the production and bioavailability of endothelium-derived NO (26). The cGMP-dependent inhibition of RhoA/Rho-kinase has a similar pleitropic effect to statins. The eNOS allows the local regulation of vascular smooth muscle tone and cell proliferation by inhibiting the expression of Rho-kinase. Thus, eNOS and Rho-kinase act in an opposing, regulatory relationship (27). In this regard, Rho kinase inhibitors are useful for the treatment of various cardiovascular diseases associated with VSMC hypercontraction and it is highly possible that long-term inhibition of Rho-kinase suppresses the development of arteriosclerosis/atherosclerosis. Several Rho-kinase inhibitors have been identified, including Y-27632 and fasudil (28). Clinical trials also determined that Rho/ROCK pathway inhibition might contribute to the pleiotropic effects of statin therapy (29). Although, the involvement of $\mathrm{NO}$ in the vascular effect of statins is known, some investigators have reported that the effects of statins appear to be diverse and depend upon the vasculature studied $(30,31)$. No investigations have been carried out so far to assess the statininduced relaxations in the presence of Rho-kinase inhibitors. Furthermore the effect of statin treatment of the cardiac vasculature has not yet been investigated.

Thus, in the current study we aimed to determine the effects of rosuvastatin in calf cardiac vein preparations and analyze the role of Rho-kinase inhibitors, fasudil and Y-27632. This vessel was selected because it is easily accessible and appropriate for studying the direct effect of agents on the vascular smooth muscle.

\section{Materials and methods}

\section{Materials}

Serotonin (5-HT) creatinine sulfate, acetylcholine (ACh) chloride, $\mathrm{N}^{\mathrm{G}}$ nitro-L-arginine methlyl esther (L-NAME), fasudil, Y-27632 (all dissolved in distilled water) and rosuvastatin (dissolved in dimethyl sulphoxide; DMSO) were used. The concentration of DMSO in the tissue bath was always kept below $0.4 \%$ ). Rosuvastatin was a gift of Abdi İbrahim Drug Company, Istanbul, Turkey. The other material was obtained from Sigma (St. Louis, MO, USA).

\section{Preparations}

Calf hearts were obtained from a slaughterhouse and immediately placed in Krebs-Henseleit solution. Segments of the great cardiac vein were removed and cut into rings $2.5 \mathrm{~mm}$ in length. Care was taken not to damage the endothelium. Each ring was mounted in $25 \mathrm{ml}$ organ baths containing Krebs-Henseleit solution (KHS), aerated with $95 \% \mathrm{O}_{2}$ and $5 \% \mathrm{CO}_{2}$. KHS was composed of (mM): $\mathrm{NaCl} 119, \mathrm{KCl} 4.70, \mathrm{MgSO}_{4} 1.50, \mathrm{KH}_{2} \mathrm{PO}_{4} 1.20, \mathrm{CaCl}_{2} 2.50$, $\mathrm{NaHCO}_{3} 25$, and glucose 11. Changes in isometric tension were recorded by a force-displacement transducer (BIOPAC MP36, Santa Barbara, California, USA) connected through amplifiers to ITBS08 Integrated Tissue Bath System (Commat, Ankara, Turkey). The tissues were allowed to equilibrate for $60 \mathrm{~min}$ under a resting tension of $1 \mathrm{~g}$ with repeated washing every $15 \mathrm{~min}$.

The endothelial cell integrity was determined in each ring before all experiments. Relaxation responses to $\mathrm{ACh}\left(10^{-6} \mathrm{M}\right)$ in rings pre-constricted with 5-HT $\left(10^{-6} \mathrm{M}\right)$ were used to test endothelial cell integrity. Preparations that had been relaxed by $>70 \%$ of 5-HT-induced tone after addition of ACh were considered to have had undamaged endothelium. In some experiments we employed denuded rings. Endothelium-denuded rings were prepared by turning the rings gently several times on the distal portion of small forceps. Endothelial integrity was pharmacologically assessed by $\mathrm{ACh}$-induced vasodilatation $\left(10^{-6} \mathrm{M}\right)$; segments showing no relaxation were considered to be denuded of endothelium. Thereafter, experimental procedures were performed as describe below.

\section{Experimental protocol}

After the equilibration period, cardiac vein preparations were contracted with $10^{-6} \mathrm{M}$ 5-HT. After the contraction had reached steady state, rosuvastatin was added to the organ bath cumulatively $\left(10^{-9}-10^{-4} \mathrm{M}\right)$. The maximal 5 -HT contraction was used as a standard by which subsequent responses of the tissue could be expressed (as a percentage of this contraction).

As rosuvastatin induced a relaxant effect in the presence of endothelium, the concentration-response curves were obtained

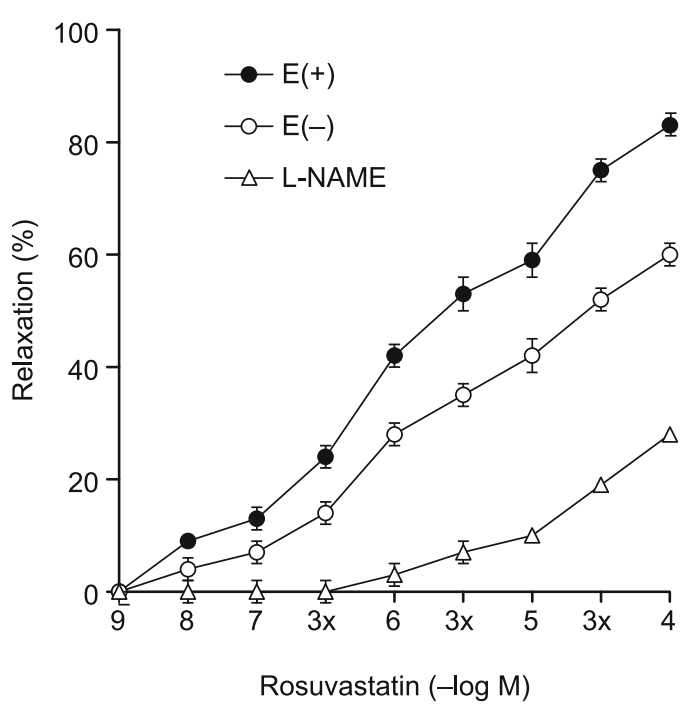

Fig. 1. Responses of rosuvastatin $\left(10^{-9}-10^{-4} \mathrm{M}\right)$ in 5 -HT $\left(10^{-6} \mathrm{M}\right)$-precontracted calf cardiac vein with $E(+)$ and without $E(-)$ endothelium, $n=6$. 


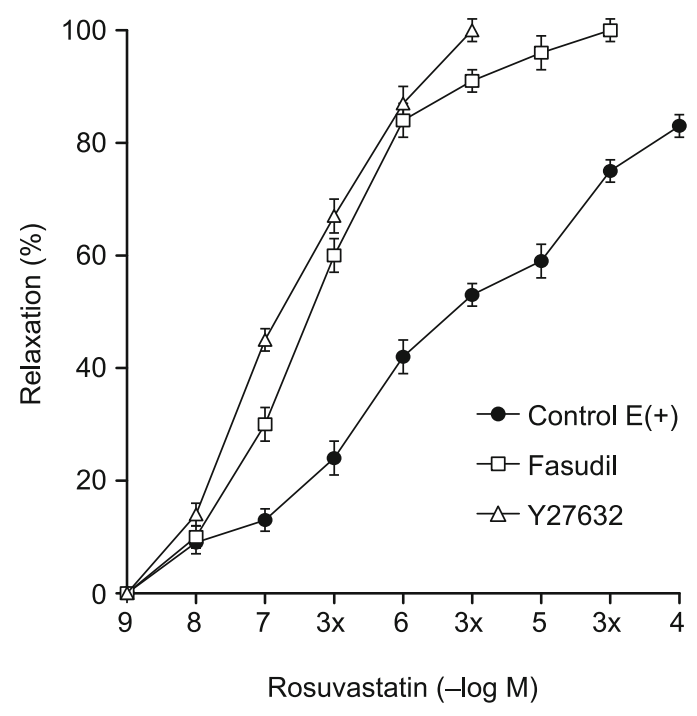

Fig. 2. Responses of rosuvastatin $\left(10^{-9}-10^{-4} \mathrm{M}\right)$ in 5-HT $\left(10^{-6} \mathrm{M}\right)$-precontracted calf cardiac vein with endothelium (control) and in presence of fasudil $\left(10^{-6} \mathrm{M}\right)$ or $\mathrm{Y}-27632\left(10^{-6} \mathrm{M}\right), \mathrm{n}=6$.

after treatment with the nitric oxide synthase inhibitor $\mathrm{N}^{\mathrm{G}}$ nitroL-arginine methyl esther (L-NAME, $10^{-4} \mathrm{M}$ ). L-NAME had been added to the organ bath $20 \mathrm{~min}$ before rosuvastatin concentrationresponse curves were obtained.

After the first concentration-response curve had been completed, preparations were washed and allowed to reestablish the resting tension. To determine the role of Rho-kinase action on rosuvastatin-induced relaxations in absence as well as in presence of endothelium, aortic rings precontracted with 5-HT were tested in the presence of fasudil $\left(10^{-6} \mathrm{M}\right)$, or Y-27632 $\left(10^{-6} \mathrm{M}\right)$ and concentration-response curves were obtained.

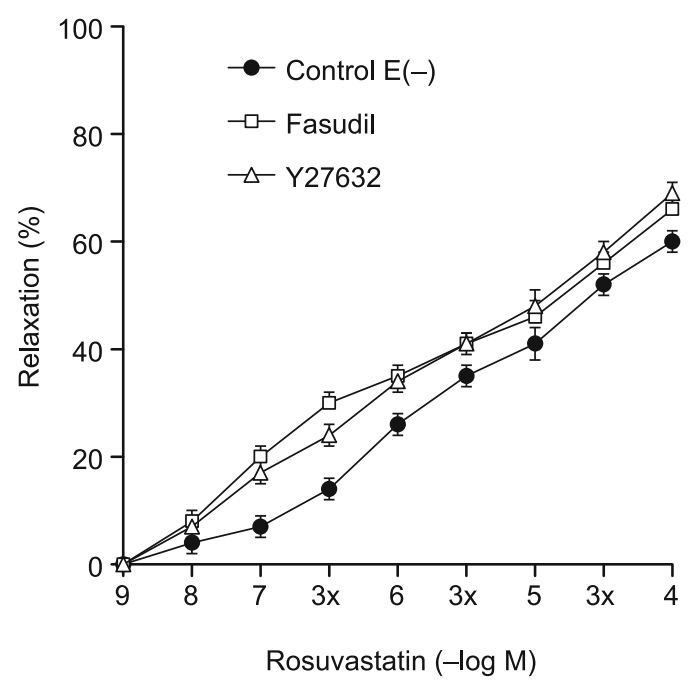

Fig. 3. Responses of rosuvastatin $\left(10^{-9}-10^{-4} \mathrm{M}\right)$ in $5-\mathrm{HT}\left(\mathbf{1 0}^{-6} \mathrm{M}\right)$-precontracted calf cardiac vein without endothelium (control) and in presence of fasudil $\left(10^{-6} \mathrm{M}\right)$ or $\mathrm{Y}-27632\left(10^{-6} \mathrm{M}\right), \mathbf{n}=6$.
Statistical analysis

Relaxation responses to rosuvastatin were expressed as percentages of 5-HT $\left(10^{-6} \mathrm{M}\right)$-induced contraction. Concentrations of rosuvastatin causing $50 \%$ of the maximal response $\left(\mathrm{IC}_{50}\right)$ were calculated from each individual concentration-response curves. Maximal responses $\left(\mathrm{E}_{\max }\right)$ and $\mathrm{pIC}_{50}\left(-\log \mathrm{IC}_{50}\right)$ values for curves were compared by using Student's t test. Data are presented as mean \pm SE. Statistical significance was set at $p<0.05$.

\section{Results}

Effect of rosuvastatin on cardiac vein rings with and without endothelium precontracted with 5-HT

As shown in Figure 1, rosuvastatin $\left(10^{-9}-10^{-4} \mathrm{M}\right)$ elicited a concentration-dependent relaxation of 5-HT-induced contractions in cardiac vein rings both with and without endothelium. However, the relaxation was lesser in the absence of endothelium. The $\mathrm{pIC}_{50}$ values were $5.65 \pm 0.23$ vs $4.59 \pm 0.20$, and maximal relaxations were $83.0 \%$ vs $60.0 \%$ in the presence and absence of endothelium, respectively. The $\mathrm{pIC}_{50}$ value of rosuvastatin was significantly lower in the preparations denuded of endothelium $(\mathrm{p}<0.05)$.

Effect of L-NAME on the relaxation induced by rosuvastatin in cardiac vein

As shown in Figure 1, pretreatment with L-NAME produced a significant rightward shift in the relaxation curve obtained by rosuvastatin. The maximal relaxant effect was reduced significantly in the presence of L-NAME $(28.0 \%)$.

Effects of fasudil and Y-27632 on the relaxant effect induced by rosuvastatin in cardiac vein rings with and without endothelium

As shown in Figure 2, pretreatment with Rho-kinase inhibitor fasudil or Y-27632 produced a significant leftward shift in the relaxation curve for rosuvastatin in rings with endothelium. The $\mathrm{pIC}_{50}$ values were $6.66 \pm 0.02$ and $6.89 \pm 0.01$, respectively, and the maximal relaxations were $100 \%$ in the presence of fasudil or Y-27632.

Furthermore, as shown in Figure 3, the pretreatment with fasudil or Y-27632 in rings denuded of endothelium significantly decreased both the $\mathrm{pIC}_{50}$ value and maximal relaxation of rosuvastatin. The $\mathrm{pIC}_{50}$ values were $4.41 \pm 0.24$ and $4.69 \pm 0.60$, and the maximal relaxations were $66.0 \%$ to $69.0 \%$ in the presence of fasudil or Y-27632 in the absence of endothelium, respectively. Compared with endothelium-denuded rings, endothelium-intact vessels exhibited increased vasodilator sensitivity to rosuvastatin in the presence of fasudil or Y-27632, suggesting the endogenous inhibition of Rho-kinase activity by an endothelium-derived agent.

\section{Discussion}

The results of the present study clearly show that rosuvastatin has an acute relaxant effect on calf cardiac vein smooth muscle, which is in agreement with previous reports evaluating the vascular effects of different statins on isolated rat aortic rings (3, 4, 17). It even has been reported that the effects of statins appear to 
be diverse and depend upon the vasculature studied $(30,31)$. To our knowledge, this is the first report showing that rosuvastatininduced endothelium-dependent relaxations and Rho-kinase inhibition increased these relaxations in the presence of endothelium layer.

As in rat aorta with simvastatin, cerivastatin and rosuvastatin $(6,32,33)$, in calf cardiac vein, we found that the vascular endothelium layer plays a very important role in the relaxant effect of rosuvastatin. In the absence of endothelium, the relaxant effect of this statin was strongly but not totally inhibited, which clearly demonstrates that the endothelium participates in this relaxation. Our results also demonstrated that in the presence of NO synthase inhibitor L-NAME, the relaxant effect of rosuvastatin was strongly inhibited. This clearly demonstrates that the endothelium participates in this relaxation through the liberation of NO. This finding is in line with the finding of Lopez et al. (6) in rat aorta. The facts that endothelium-mediated relaxation in cardiac vein rings relies greatly on the production of $\mathrm{NO}$, and that the inhibitory effect of L-NAME in our study seemed to be higher than that obtained with the removal of endothelium suggest that the vascular smooth muscle may also produce NO in response to rosuvastatin, although in smaller quantities than those produced by endothelium.

Numerous studies have suggested that the inhibition of RhoA/ Rho-kinase-mediated $\mathrm{Ca}^{2+}$ sensitization induces the relaxation of vascular smooth muscle $(31,34)$. And because Rho-kinase isoforms are expressed not just in vascular smooth muscle but also in endothelial cells (35), and because RhoA/Rho-kinase activation and NO production/signaling pathways may be interconnected (36), we further assessed whether endothelium and especially NO could be mediating the responses of fasudil and Y-27632 in calf cardiac vein. In the present study, it is apparent that both Rho-kinase inhibitors increased the rosuvastatin-induced relaxations in the presence of endothelium. It is known that inhibition of Rho-kinase may contribute to some of cholesterol-independent effects of statins by increasing the expression of endothelial nitric oxide synthase (eNOS) $(37,38)$. Specifically, the reduction in geranylgeranyl pyrophosphate after statin treatment reduces the activity of RhoA and Rho-kinase. This results in stabilization of eNOS mRNA and increased bioavailability of nitric oxide (NO) $(37,39)$. Another important pathway of eNOS activation in endothelial cells is the post-translational phosphorylation of eNOS by protein kinase Akt $(40,41)$. Because the increased Rho-kinase activity is associated with cardiovascular risks such as hypertension (42), it is quite likely that eNOS regulation by Rho-kinase may play an important role in the pathogenesis of cardiovascular diseases. Moreover, Wolfrum et al (43) reported that acute inhibition of Rho-kinase leads to cardiovascular protection mediated by rapid activation of eNOS. As in our study, Chitaley and Webb (44) also reported that in the absence of endothelium, Y-27632 was an ineffective inhibitor of phenylephrine-induced contraction.

In summary, the findings of the present study support the hypothesis that endogenous NO-induced relaxation occurs principally through the inhibition of RhoA/Rho-kinase activity in the intact calf cardiac vein. This provides a novel insight into a prominent vasodilation pathway.

\section{References}

1. Jukema JW, Bruschke AV, van Boven AJ et al. Effects of lipid lowering by pravastatin on progression and regression of coronary artery disease in symptomatic men with normal to moderately elevated serum cholesterol levels. The Regression Growth Evaluation Statin Study (REGRESS). Circulation 1995; 91: 2528-2540.

2. Riegger G, Abletshauser C, Ludwig M et al. The effect of fluvastatin on cardiac events in patients with symptomatic coronary artery disease during one year of treatment. Atherosclerosis 1999; 144: 263-270.

3. Corsini A, Pazzucconi F, Arnaboldi L et al. Direct effects of statins on the vascular wall. J Cardiovasc Pharmacol 1998; 31: 773-778.

4. Alvarez De Sotomayor M, Herrera MD, Marhuenda E, Andriantsitohaina R. Characterization of endothelial factors involved in the vasodilatory effect of simvastatin in aorta and small mesenteric artery of the rat. Br J Pharmacol 2000; 131: 1179-1187.

5. Sonmez Uydes-Dogan B, Topal G, Takir S et al. Relaxant effects of pravastatin, atorvastatin and cerivastatin on isolated rat aortic rings. Life Sci 2005; 76: 1771-1786.

6. Lopez J, Mendoza R, Cleva VG et al. Participation of $\mathrm{K}^{+}$channels in the endothelium-dependent and endothelium-independent components of the relaxant effect of rosuvastatin in rat aortic rings. J Cardiovasc Pharmacol Ther 2008; 13: 207-213.

7. Laufs U, La Fata V, Plutzky J, Liao JK. Upregulation of endothelial nitric oxide synthase by HMG CoA reductase inhibitors. Circulation 1998; 97: 1129-1135.

8. Kolyada AY, Fedtsov A, Madias NE. 3-Hydroxy-3-methylglutaryl coenzyme A reductase inhibitors upregulate inducible NO synthase expression and activity in vascular smooth muscle cells. Hypertension 2001; 38: 1024-1029.

9. Ridker PM, Danielson E, Fonseca FA et al. Rosuvastatin to prevent vascular events in men and women with elevated $\mathrm{C}$-reactive protein. $\mathrm{N}$ Engl J Med 2008; 359: 2195-2207.

10. Cooke JP, Rossitch E Jr, Andon NA et al. Flow activates an endothelial potassium channel to release an endogenous nitrovasodilator. J Clin Invest 1991; 88: 1663-1671.

11. Perrella MA, Edell ES, Krowka MJ et al. Endothelium-derived relaxing factor in pulmonary and renal circulations during hypoxia. Am J Physiol 1992; 263: R45-R50.

12. Wolfrum S, Jensen KS, Liao JK. Endothelium-dependent effects of statins. Arterioscler Thromb Vasc Biol 2003; 23: 729-736.

13. Assmann G, Schulte H, von Eckardstein A, Huang Y. High density lipoprotein cholesterol as a predictor of coronary heart disease. The PROCAM experience and pathophysiological implications for reverse cholesterol transport. Atherosclerosis 1996; 124 (Suppl): S11-S20.

14. Pedersen TR. Coronary artery disease: the Scandinavian Simvastatin Survival Study (4S) experience. Am J Cardiol 1998; 82: 53T-56T.

15. Sacks FM, Pfeffer MA, Moyé LA et al. The effect of pravastatin on coronary events after myocardial infarction in patients with average cholesterol levels. N Engl J Med 1996; 335: 1001-1009.

16. Shepherd J, Cobbe SM, Ford I. Prevention of coronary heart disease with pravastatin in men with hypercholesterolemia. N Engl J Med 1995; 333: 1301-1307.

17. Takai Y, Sasaki T, Matozaki T. Small GTP-binding proteins. Physiol Rev 2001; 81: 153-208. 
494-498

18. Fukata Y, Amano M, Kaibuchi K. Rho-Rho-kinase pathway in smooth muscle contraction and cytoskeletal reorganization of non-muscle cells. Trends Pharmacol Sci 2001; 22: 32-39.

19. Shimokawa H. Cellular and molecular mechanisms of coronary artery spasm: lessons from animal models. Jpn Circ J 2000; 64: 1-12.

20. Kandabashi T, Shimokawa H, Mukai Y et al. Involvement of Rhokinase in agonists-induced contractions of arteriosclerotic human arteries. Arterioscler Thromb Vasc Biol 2002; 22: 243-248.

21. van Nieuw Amerongen GP, van Delft S, Vermeer MA et al. Activation of RhoA by thrombin in endothelial hyperpermeability: role of Rho kinase and protein tyrosine kinases. Circ Res 2000; 87: 335-340.

22. van Nieuw Amerongen GP, Vermeer MA, van Hinsbergh VW. Role of RhoA and Rho kinase in lysophosphatidic acid-induced endothelial barrier dysfunction. Arterioscler Thromb Vasc Biol 2000; 20: E127-133.

23. 23 Cario-Toumaniantz C, Evellin S, Maury S et al. Role of Rho kinase signalling in healthy and varicose human saphenous veins. Br J Pharmacol 2002; 137: 205-212.

24. Sauzeau V, Le Jeune H, Cario-Toumaniantz C, Smolenski A, Lohmann SM, Bertoglio J. et al. Cyclic GMP-dependent protein kinase signaling pathway inhibits RhoA-induced $\mathrm{Ca}^{2+}$ sensitization of contraction in vascular smooth muscle. J Biol Chem 2000; 275: 21722-21729.

25. Shirao S, Kashiwagi S, Sato M et al. Sphingosylphosphorylcholine is a novel messenger for Rho-kinase-mediated $\mathrm{Ca}^{2+}$ sensitization in the bovine cerebral artery: unimportant role for protein kinase C. Circ Res 2002; 26: 112-119.

26. Kosmidou I, Moore JP, Weber M, Searles CD. Statin treatment and 3' polyadenylation of eNOS mRNA. Arterioscler. Thromb Vasc Biol 2007; 27: 2642-2649.

27. Takemoto M, Sun J, Hiroki J, Shimokawa H, Liao JK. Rho-kinase mediates hypoxia induced downregulation of endothelial nitric oxide synthase. Circulation 2002; 106: 57-62.

28. Uehata M, Ishizaki T, Satoh H, Ono T, Kawahara T, Morishita T et al. Calcium sensitization of smooth muscle mediated by a Rho associated protein kinase in hypertension. Nature 1997; 389: 990-994.

29. Pasterkamp G, van Lammeren GW. Pleiotropic effects of statins in atherosclerotic disease. Cardiovasc Ther 2010; 8: 1235-1237.

30. Fleischmann EH, Schlaich MP, Schmidt BM, Oehmer S, Schmieder RE. Hypercholesterolaemia and treatment with statins do not alter 1-arginine-induced changes of renal haemodynamics. Nephrol Dial Transplant 2002; 17 (10): 1758-1765.
31. John S, Delles C, Jacobi J et al. Rapid improvement of nitric oxide bioavailability after lipid-lowering therapy with cerivastatin within two weeks. J Am Coll Cardiol 2001; 37 (5): 1351-1358.

32. Sowers JR. Effects of statins on the vasculature: implications for aggressive lipid management in the cardiovascular metabolic syndrome. Am J Cardiol 2003; 91: 14B-22B.

33. Rüdiger C, Gast CH, Li F et al. Cerivastatin activates endothelial calcium-activated potassium channels and thereby modulates endothelial nitric oxide production and cell proliferation. J Am Soc Nephrol 2004; 15: $868-875$.

34. Amano M, Fukata Y, Kaibuchi K. Regulation and functions of Rhoassociated kinase. Exp Cell Res 2000; 261: 44-51.

35. Loirand G, Guerin P, Pacaud P. Rho kinases in cardiovascular physiology and pathophysiology. Circ Res 2006; 98: 322-334.

36. Seasholtz TM, Brown JH. Rho signaling in vascular diseases. Mol Interv 2004; 4: 348-357.

37. Takemoto M, Sun J, Hiroki J et al. Rho-kinase mediates hypoxiainduced downregulation of endothelial nitric oxide synthase. Circulation 2002; 106: 57-62.

38. Wolfrum S, Jensen KS, Liao JK. Endothelium-dependent effects of statins. Arterioscler Thromb Vasc Biol 2003; 23: 729-736.

39. Laufs U, Liao JK. Post-transcriptional regulation of endothelial nitric oxide synthase mRNA stability by Rho GTPase. J Biol Chem 1998; 273: 24266-24271.

40. Dimmeler S, Fleming I, Fisslthaler B et al. Activation of nitric oxide synthase in endothelial cells by Akt- dependent phosphorylation. Nature 1999; 399: 601-605.

41. Fulton D, Gratton JP, McCabe TJ et al. Regulation of endotheliumderived nitric oxide production by the protein kinase Akt. Nature 1999; 399: 597-601.

42. Mukai Y, Shimokawa H, Matoba T et al. Involvement of Rho-kinase in hypertensive vascular disease: a novel therapeutic target in hypertension. FASEB J 2001; 15: 1062-1064.

43. Wolfrum S, Dendorfer A, Rikitake Y et al. Inhibition of Rho-kinase leads to rapid activation of phosphatidylinositol 3-kinase/protein kinase Akt and cardiovascular protection. Arterioscler Thromb Vasc Biol 2004; 24: $1842-1847$.

44. Chitaley K, Webb RC. Nitric oxide induces dilation of rat aorta via inhibition of Rho-kinase signaling. Hypertension 2002; 39: 438-442.

Received July 1, 2014. Accepted April 2, 2015. 